\title{
ATENÇÃO FARMACÊUTICA NA ANTIBIOTICOTERAPIA
}

\author{
PHARMACEUTICAL ASSISTANCE IN ANTIBIOTICS THERAPY
}

\author{
OLIVEIRA, Antonio Otávio T. de 1,3,5; PEDROSO, Carlos F.1,5; MIGUEL, Marilis D. 2,3,; \\ MONTRUCCHIO, Deise P. ; ZANIN, Sandra Maria W. ${ }^{2,3}$; DORNELES, Daniela ${ }^{2,3}$
}

\begin{abstract}
* Projeto: Atenção Farmacêutica na Formação do Acadêmico de Farmácia - NIPCF-UFPR
Endereço para correspondência: e-mail: dallarmi@onda.com.br

1-Aluno da Graduação do Curso de Farmácia da UFPR;

2-Professora da disciplina de Farmacotécnica I e II - UFPR;

3-Projeto de Atenção Farmacêutica na Formação do Acadêmico de Farmácia NIPCF-UFPR;

4-Professora da disciplina de Estágio Supervisionado em Farmácia - UFPR;

5-Farmacêutico.
\end{abstract}

Recebido em: 12/2003

Aprovado em: 03/2004

RESUMO

A escolha correta do antimicrobiano requer diagnóstico clínico laboratorial (identificação do agente infeccioso e antibiograma) e conhecimento farmacológico das drogas utilizadas na terapêutica. Os antibióticos são dispensados livremente nas farmácias sem necessidade de prescrição médica, favorecendo a aparecimento de problemas como terapia ineficaz, resistência bacteriana e indução da auto medicação, uma vez que balconistas recebem comissão na venda de medicamentos. $\bigcirc$ atendimento requer a atenção farmacêutica onde se possa realizar a anamnese do paciente, estabelecendo-se um sistema seguro, efetivo e que beneficia a farmacoterapia com o objetivo de obter resultados terapêuticos definidos na saúde e qualidade de vida do paciente. Palavras-chave: atenção farmacêutica, antibióticos, resistência bacteriana.

ABSTRACT

The correct choice of an antimicrobial therapy requires clinical and laboratorial diagnosis (identification of infectious agent and antibiogram) and pharmacological knowledge of drugs used in therapeutics. Antibiotics are freely dispensed in drugstores with no need of medical prescription, leading to the appearance of problems such as inefficient therapy, bacterial resistance and induction of selfmedication, once sellers receive commission on sales of medicine. The correct selling requires the pharmaceutical care, when it's possible to collect information from the patient, establishing a safe and effective system that benefits the pharmacotherapy in order to reach defined therapeutic results on health and quality of life of patient.

Keywords: pharmaceutical care, antibiotics, bacterial resistance

INTRODUÇÃO

Os antibióticos foram primeiramente definidos como substâncias químicas produzidas por várias espécies de microrganismos, vegetais e animais, que impedem o crescimento de outros. Contudo, o desenvolvimento da industria farmacêutica viabilizou a síntese de antibióticos de origem semi-sintética e sintética (TAVARES, 1990).

Estes diferem entre si quanto às propriedades químicas, seus espectros e mecanismos de ação e são classificados quimicamente como: derivados de aminoácidos, de açúcares, de acetatos, propionatos, entre outros (TAVARES, 1990).

Os antibióticos são medicamentos de venda sob prescrição médica, contudo são dispensados livremente nas farmácias sem a apresentação da prescrição ou diagnóstico laboratorial, e ainda, os balconistas geralmente recebem comissão sobre as vendas de medicamentos. Estes são os principais fatores que levam ao uso indiscriminado, e muitas vezes inadequado dos antibióticos, favorecendo a ocorrência de resistência bacteriana e ineficácia terapêutica.

A resistência bacteriana aos antibióticos está associada a seu uso inadequado. 0 
mecanismo celular dessa resistência deve-se a uma modificação genética estável, transmissível através das gerações. Apesar da mutação ser freqüentemente a causa dessa resistência, outros mecanismos de transferência do material genético estão envolvidos, como a transdução, transformação, conjugação, elementos extracromossomais (plasmídeos) e DNA recombinante (TRABULSI et al., 1999; MAHON; MANUSELIS, 1995; MIMS et al., 1999).

A escolha racional do antimicrobiano é um processo complexo, que exige diagnóstico clínico laboratorial e conhecimento farmacológico dos agentes infecciosos. Logo, essa escolha deve ser realizada por um profissional habilitado e qualificado, e representa um desafio para os médicos e farmacêuticos.

No tratamento de uma infecção com um antimicrobiano, a escolha, a dosagem, a via de administração e o tempo de tratamento, podem representar a eficiência da terapêutica. Nem sempre é possível definir o agente etiológico e o conseqüente antibiograma, portanto a escolha do antibiótico deve considerar o local de ação, a flora bacteriana normal neste, os prováveis agentes etiológicos, perfil de sensibilidade, resistência dos microrganismos aos agentes antimicrobianos e o custo dos mesmos (BISSON, 2003).

Uma vez selecionado o antimicrobiano e prescrito pelo profissional responsável, cabe ao farmacêutico a orientação e acompanhamento na administração do mesmo, proporcionando maior segurança e eficiência na terapêutica (ANSEL et al., 2000; BISSON, 2003).

Entretanto, fatores como a auto medicação, a indicação e dispensação de um fármaco pelo balconista (leigo), contribuem ao uso indiscriminado dos antibióticos. Essa ocorrência se dá em nível nacional e representa uma atitude irresponsável por parte dos farmacêuticos que delegam ao balconista a indicação e dispensação de todo e qualquer medicamento. O referido profissional, torna-se cúmplice no processo, cujos erros e enganos de seu preposto depõem contra a eficiência do tratamento (LEI n० 9787, 1999).

Nesse contexto buscou-se, por meio da referida pesquisa, além da aproximação do acadêmico com a realidade histórica da dispensação de antibióticos, proporcionar uma visão crítica que viabilize apontar caminhos de melhoria no quadro instalado nas farmácias curitibanas.

\section{METODOLOGIA}

Foi realizada uma pesquisa sobre dispensação de antibióticos, em uma farmácia na região central de Curitiba, no Estado do Paraná. A investigação ocorreu no segundo semestre de 2003, onde foram constatadas 330 dispensações de antibióticos, sendo $42 \%$ para homens e 58\% para mulheres. Buscou-se destacar os antibióticos mais utilizados, a forma farmacêutica mais dispensada, sexo dos usuários, presença ou ausência de prescrições médicas, e os dados foram registrados em uma tabela específica. Esta foi devidamente preenchida sempre que houve a dispensação de antibióticos. Cabe ressaltar que o preenchimento foi realizado pelo farmacêutico, balconistas e estagiários.

A metodologia de pesquisa qualitativa propôs uma ação coletiva sob a óptica participativa, onde pesquisados e pesquisadores beneficiaram-se da construção do conhecimento, no momento da dispensação (BRANDÃO, 1990; TRUJILLO, 1982; MIGUEL; MIGUEL, 2000). 


\section{RESULTADOS E DISCUSSÃO}

Quanto aos antibióticos mais dispensados: os dados obtidos são representados no Gráfico 1, que apresenta a amoxicilina, uma penicilina de $2^{a}$ geração (GILMAN; HARDMAN; LIMBIRD, 1996) como o antibiótico mais requisitado no período da pesquisa, provavelmente pelo seu largo espectro de ação bactericida (MIMS et al., 1999), evidenciando ser freqüentemente utilizado em infecções, principalmente de garganta, comum nas estações de temperaturas amenas. O segundo antimicrobiano mais requisitado foi a ciprofloxacina, uma Fluorquinolona de $2^{a}$ geração (GILMAN; HARDMAN; LIMBIRD, 1996), que apresenta grande espectro de ação, por ser um agente sintético que impede o superespiralamento do cromossoma bacteriano (MIMS et al., 1999), sendo muito utilizada para diversos tipos de infecções. A cefalexina, uma cefalosporina pertencente à classe dos b-lactâmicos, foi o terceiro antimicrobiano mais dispensado, devido seu amplo espectro de ação, segurança e mecanismos de ação (GILMAN; HARDMAN; LIMBIRD, 1996; MIMS et al., 1999; RxList Drug Index).

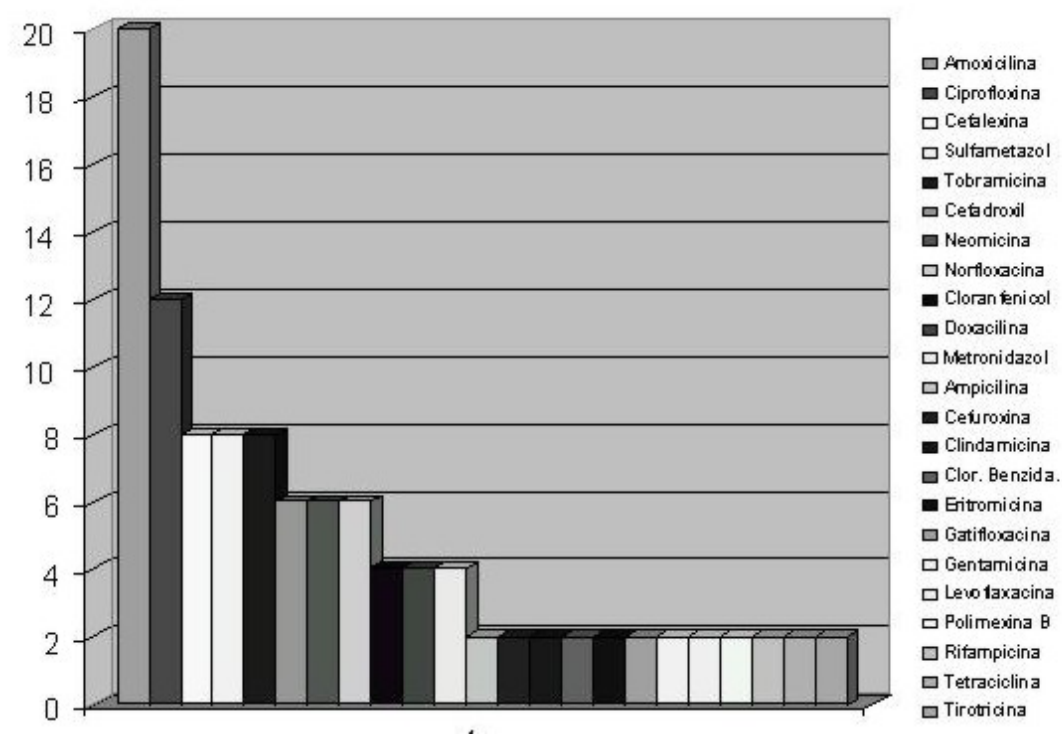

GRÁFICO 1: ANTIBIÓTICOS MAIS DISPENSADOS

A pesquisa chama a atenção para a percentagem de Ciprofloxacina dispensada, por ser este um antimicrobiano que está perdendo eficiência contra bacilos gram-negativos, devido ao uso indiscriminado do mesmo pela população (NEUHAUSER, 2003).

Esse dado revela a situação da saúde pública em Curitiba, onde se receitam e dispensam-se antibióticos potentes. Tal situação ocorre devido anamnese médica sem suporte laboratorial (antibiograma), realizada rapidamente, principalmente pelos médicos que atendem pelos planos de saúde e sistema único de saúde (SUS).

O uso indiscriminado dos antibióticos muito potentes é problemático, e esse é considerado o grande vilão da corrida entre bactérias e antimicrobianos, sendo um dos fatores responsáveis pela indução de resistência em cepas bacterianas e perda gradativa da eficiência terapêutica.

É necessária uma conscientização não só dos profissionais da saúde, que pode se viabilizar por meio de formação acadêmica plena voltada para o sentido de beneficiar e valorizar o homem enquanto paciente e usuário do medicamento, mas também das 
empresas envolvidas e as instituições públicas de atendimento à saúde. A utilização da forma correta do medicamento otimiza sua eficácia, segurança e diminui a necessidade de antibióticos mais potentes, consequentemente, minimiza os gastos com medicamentos (MIGUEL et al., 2002).

As formas farmacêuticas mais dispensadas são apresentadas no Gráfico 2, sendo as formas sólidas (comprimidos, drágeas, cápsulas) aquelas mais prescritas pelo fato de ser a forma de administração de maior facilidade e comodidade ao paciente.

Alguns antibióticos não se apresentam nesta forma, devido aos aspectos de estabilidade e biodisponibilidade, como exemplo os aminoglicosídeos, que são dispensados normalmente para uso tópico ou injetável. As formas líquidas (suspensão, colírios, soluções, injetáveis, spray) foram pouco dispensadas e as semi-sólidas (pomada, creme) menos ainda, provavelmente pela especificidade de seu uso em queimaduras, lesões cutâneas e problemas oculares.

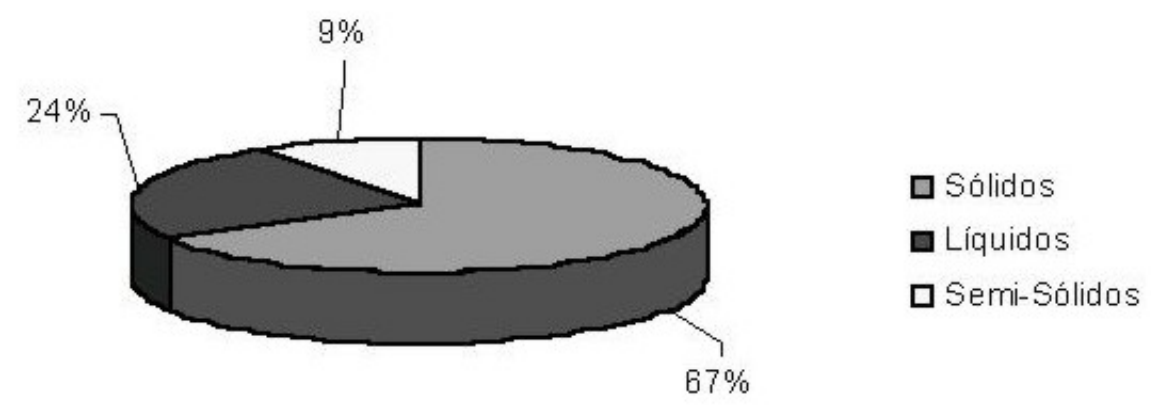

GRÁFICO 2: FORMAS FARMACÊUTICAS MAIS DISPENSADAS.

De acordo com a Lei n 9787, de 10/02/1999, os medicamentos podem ser classificados em:

- Medicamento de Referência - produto inovador registrado no órgão federal responsável pela vigilância sanitária e comercializado no País, cuja eficácia, segurança e qualidade foram comprovadas cientificamente junto ao órgão federal competente, por ocasião do registro;

- Medicamento Similar - aquele que contém o mesmo ou as mesmas substâncias ativas, apresenta a mesma concentração, forma farmacêutica, via de administração, posologia e indicação terapêutica, preventiva ou diagnóstica, do medicamento de referência registrado no órgão federal responsável pela vigilância sanitária, podendo diferir somente em características relativas ao tamanho e forma do produto, prazo de validade, embalagem, rotulagem, excipientes e veículos, devendo sempre ser identificado por nome comercial ou marca;

- Medicamento Genérico - medicamento similar a um produto de referência ou inovador, que se pretende ser com este intercambiável, geralmente produzido após a expiração ou renúncia da proteção patentária ou de outros direitos de exclusividade, comprovada a sua eficácia, segurança e qualidade, e designado pela Denominação Comum Brasileira (DCB) ou, na sua ausência, pela Denominação Comum Internacional (DCl).

Em relação à classificação dos antibióticos (referência, similares e genéricos), os similares foram dispensados quase tanto quanto aqueles considerados éticos (medicamentos de 
referência) e os genéricos foram dispensados em quantidade desprezível, como mostra o Gráfico 3.
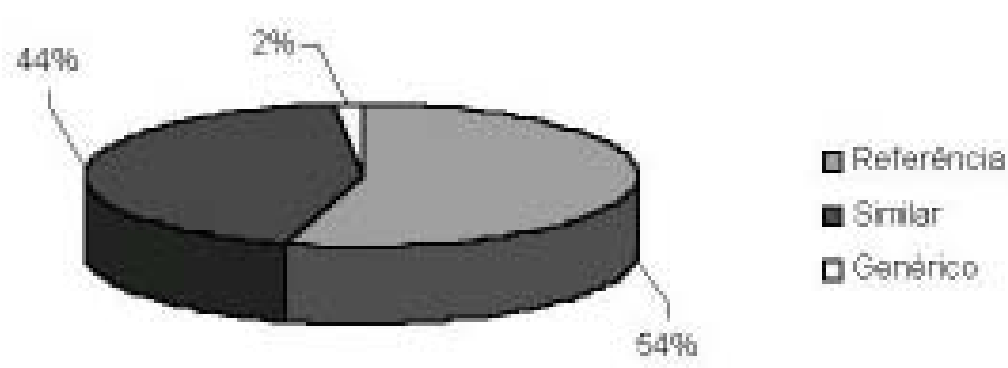

GRÁFICO 3: CLASSIFICAÇÃO DOS ANTIBIÓTICOS QUANTO A SUA ORIGEM

Os similares apresentaram uma percentagem elevada na dispensação de antibióticos, mesmo sendo incomum um médico prescrever uma receita com o nome do similar, mas sim com o nome de referência ou da substância ativa; esse último refere-se ao genérico.

Observa-se portanto que freqüentemente a dispensação de medicamentos similares ocorre por meio da auto medicação ou pela indução do balconista. Este utiliza a receita médica destinada aos genéricos, contendo o nome da substância ativa, para dispensar o similar. O vendedor recebe comissão de venda, qual pode variar de $8 \%$ a $18 \%$ nos diversos estabelecimentos farmacêuticos.

A comercialização de artigos de perfumaria, revistas, alimentos, bebidas e de medicamentos, principalmente os chamados similares, representam grande parte dos lucros da farmácia, além de serem os responsáveis pela vantajosa margem de lucro aos balconistas. Para ilustrar esse caso, existem farmácias em Curitiba, em que o balconista recebe o dobro do salário do farmacêutico, somente em comissões.

Os interesses econômicos sobrepõem-se à terapêutica e à qualidade de vida dos pacientes, prática esta que impede a ação do profissional farmacêutico na dispensação. Detectou-se que o mesmo somente pode intervir na dispensação se sua presença for solicitada no momento da mesma. Não se trata de ser contra ou a favor dos medicamentos similares, mas sim pela correta dispensação do medicamento de acordo com a prescrição médica, além do esclarecimento ao paciente sobre as diferenças entre os medicamentos.

Durante o período de realização da pesquisa, além dos dados obtidos, também procurou-se observar as dúvidas mais freqüentes e as respectivas orientações repassadas no momento da dispensação. Constatou-se que poucos indivíduos questionam sobre os riscos, o modo de ação e a forma de uso dos antibióticos, provavelmente pela falta de conhecimento da população sobre os problemas da má administração de fármacos, os quais são responsáveis pelos problemas relacionados ao medicamento (PRM) (PERETTA; CICCIA, 2000).

A dispensação de antibióticos, sem qualquer orientação aos pacientes, representa uma prática comum na maioria das farmácias de Curitiba. A conseqüência deste ato desprovido de responsabilidade ética acaba acarretando uma terapia ineficaz, e gera problemas como resistência bacteriana, potencialização dos efeitos adversos, falta de monitoramento e orientação quanto à dose, forma de uso e tempo do tratamento.

A classificação dos PRM torna-se útil por diversas razões, dentre estas destacam-se as 
reações adversas ao medicamento (RAM) como uma categoria do PRM existentes. Este enfatiza a necessidade do desenvolvimento de mecanismos pelos quais os farmacêuticos possam identificar, resolver, prevenir, quantificar, predizer e intervir em PRM de todos os tipos (STRAND et al., 1990), além de viabilizar o atendimento específico a cada prescrição.

Contudo, nesta perspectiva o atendimento requer a atenção farmacêutica, onde se possa realizar a anamnese do paciente, estabelecendo-se um sistema seguro, efetivo e voltado ao ser humano enquanto sujeito na administração do medicamento (STRAND et al., 1990).

Por outro lado tem-se a difícil relação de entendimento entre empresários e farmacêuticos, onde o lucro sobrepõe a terapêutica. O profissional passa a sofrer pressão entre exercer a atenção farmacêutica propriamente dita e administração lucrativa, por meio de cotas pré-estabelecidas pela empresa na comercialização de produtos.

Se os farmacêuticos e os gerentes das farmácias fossem capazes de desenvolver sistemas que colocam em operação o papel ativo do profissional, este justificaria sua função como um prazer, e não como uma tarefa desagradável e impossível (STRAND et al., 1990).

\section{CONCLUSÃO}

Percebe-se a carência de ações profissionais que visam o respeito ao ser humano, a responsabilidade ética e o conhecimento técnico e científico do profissional farmacêutico, cujo âmbito profissional é garantido em Lei Federal n³.820, de 11 de novembro de 1960. Cabe ressaltar a necessidade de se estabelecer as responsabilidades do ato de dispensar o medicamento, principalmente o antibiótico, o que reforça a importância do controle efetivo da comercialização do mesmo em virtude dos riscos e benefícios da terapêutica.

A dispensação indiscriminada dos antimicrobianos possivelmente ocorre pelo alto índice de propaganda e marketing do medicamento, somado aos aspectos culturais de auto medicação e aliado ao elevado índice de analfabetismo, qual favorece a atuação do balconista, que é comissionado, ao invés do farmacêutico. Este quadro pode mudar, com uma simples atitude do profissional farmacêutico, que inclui o exercício efetivo deste no momento da dispensação, de exercer a atenção farmacêutica com propósito de beneficiar a sociedade no atendimento primário à saúde.

A assistência farmacêutica vem de encontro a essas questões, propondo um profissional mais participativo com a comunidade e com os problemas de saúde pública. Devido às peculiaridades existentes nos diferentes fármacos, tem-se que adequar a orientação individualizada ao usuário do serviço, no que se refere ao uso racional dos medicamentos. O paciente deve ser alertado sobre os efeitos colaterais esperados, e quanto a alimentos, bebidas e/ou outros fármacos podem interferir na biodisponibilidade do medicamento e comprometer a eficiência da terapêutica (TRABULSI et al., 1999; MIGUEL; MIGUEL, 2000).

A atenção farmacêutica é o compêndio ético das atitudes, de comportamentos, de compromissos, de valores, das funções, dos conhecimentos, das responsabilidades e das habilidades do profissional no benefício da farmacoterapia, com o objetivo de obter resultados terapêuticos definidos na saúde e qualidade de vida do paciente (STRAND et al., 1990; Comission to implement change in pharmaceutical education, 1991).

Nesse contexto faz-se necessário um profissional capaz de exercer a dispensação responsável e ética para obter o resgate do prestígio da profissão farmacêutica e o reconhecimento da população de sua importância como profissional da área da saúde. 
Será inútil recorrer à ética com a esperança de encontrar nela uma forma de ação para cada situação concreta, contudo pode-se encontrar apoio no reconhecimento profissional pela população, sendo esta capaz de mudar o sistema que está posto, qual visa metas e lucros (VAZQUEZ, 1982).

É preciso implantar a atenção farmacêutica em "mão dupla", entre idas e vindas, quais estabelecem interrelações entre o médico, o farmacêutico e o paciente (OLIVEIRA e† al., 2002).

\section{REFERÊNCIAS}

ANSEL, H.C.; POPOVICH, N.G.; ALLEN JR, L.V. Formas Farmacêuticas \& Sistemas de Liberação de Fármacos. 6. ed. São Paulo: Premier, 2000.

BISSON, M.P. Farmácia Clínica e Atenção Farmacêutica. São Paulo: Medfarma, 2003.

BRANDÃO, C.R. (Org.). Pesquisa participante. 8. ed. São Paulo: Brasiliense, 1990.

BRASIL, 1960. Lei n 3820, de 11 de novembro de 1960. Disponível em <http://www.planalto.gov.br/>. Acesso em 16/02/2003.

BRASIL, 1999. Lei no 9787, de 10 de fevereiro de 1999. Disponível em: http://www.anvisa.gov.br/scriptsweb/ anvisalegis/VisualizaDocumento.asp?ID=2837\&Versao=2. Acesso em 30/10/2002.

Commission to Implement Change in Pharmaceutical Education. A position paper: Entry-level Education in Pharmacy: A Commitment to Change. American Association of Colleges of Pharmacy News. Special Report. Alexandria (Virginia), 1991.

GILMAN, A.G.; HARDMAN, J.G.; LIMBIRD, L.E. As Bases Farmacológicas da Terapêutica. 9. ed. Rio de Janeiro: Mcgraw-Hill Interamericana, 1996.

MAHON, C.R.; MANUSELIS JR, G. Textbook of Diagnostic Microbiology. Philadelphia: W.B. Saunders Company, 1995.

MIGUEL, M.D. et al. O Cotidiano das Farmácias de Manipulação. Visão Acadêmica, vol. 3 n 2 jul-dez: 103-108. Curitiba, UFPR, 2002.

MIGUEL, M.D.; MIGUEL, O.G. Atenção Farmacêutica na Formação do Acadêmico de Farmácia. Visão Acadêmica. Curitiba, UFPR, 2000.

MIMS, C.; PLAYFAIR, J.; ROITT, l.; WAKELIN, D.; WILLIAMS, R. Microbiologia Médica. 2. ed. São Paulo: Manole, 1999. NEUHAUSER, M.M. et al. Antibiotic Resistance Among Gram-Negative Bacilli in US Intensive Care Units: Implications for Fluoroquinolone Use. JAMA 2003; Feb 19; 289(7):885-888.

OLIVEIRA, A.B. et al. O Hipotireoidismo sob a Ótica Farmacêutica Generalista. Visão Acadêmica, vol. $3 \mathrm{n}^{\circ} 2$ jul-dez: 109-117. Curitiba, UFPR, 2002.

PERETTA, M.; CICCIA, G. Reengenharia Farmacêutica - Guia para Implantar Atenção Farmacêutica. Brasília: Ethosfarma, 2000

RxList Drug Index. Disponível em < http://www.rxlist.com/cgi/generic/cephalex.htm>. Acesso em 16/02/2003. STRAND, L.M.; MORLEY, P.C.; CIPOLLE, R.J.; RAMSEY, R.; AMSAM, G.D. Traducido de Ann Pharmacother 1990; $24: 1093$ 1097 (com autorización a Fundación Pharmaceutical Care España).

TAVARES, W. Manual de Antibióticos e Quimioterápicos Antiinfecciosos. São Paulo: Atheneu, 1990.

TRABULSI, L.R.; ALTERTHUM, F.; GOMPERTZ, O.F.; CANDEIAS, J.A.N. Microbiologia. 3. ed. São Paulo: Atheneu, 1999. TRUJILLO, A.F. Metodologia da pesquisa científica. São Paulo: McGraw-Hill do Brasil, 1982.

VAZQUEZ, A. S. Ética. 5. ed. Rio de Janeiro: Civilização Brasileira, 1982. 